\title{
Multi-Functional Social CRM in Cloud with Cross-Platform Mobile Application
}

\author{
Shalini Sharma \\ M.Tech (CS\&E) \\ Amity University, India
}

\author{
Satyajit Padhy \\ M.Tech (CS\&E) \\ Amity University, India
}

\author{
Vikram Verma \\ M.Tech (CS\&E) \\ Amity University, India
}

\begin{abstract}
In this paper, they try to represent the importance of communication and interaction between an organization and its clients. Cloud CRM (Customer Relationship Model) is a dynamic application that is developed with latest technologies in order to mark a remarking presence of CRM process. This is built as a web application for both the customer and clients. Cloud CRM has exceptional features like employee management system to manage employees in an organization, leads management system which is built for extensive leads generation, payroll management system for managing salaries, inventory management system, bulk SMS and bulk Email facilities for notifications and campaigning and Interactive Voice Response with virtual numbers facility for the organization. The entire project is deployed in cloud. The three major sections of this project is deployed as client interface, organization interface and mobile application. All these sections are connected to a central database in the cloud. The project is deployed in Windows Azure cloud and the cloud services makes this application dynamic. The most important features of doing so is dynamic allocation of network resources and pay per usage features makes the project more powerful. The Android mobile application is built for the clients that will be using the services of the real estate CRM. It helps in generating leads from a wider scope for the organization and at the other side the clients even get to use a portable application in this age of digitization.
\end{abstract}

\section{Keywords}

Android, CRM, Inventory, IVR, Lead Management System, Mobile Application, MySQL, Payroll, PHP, Windows Azure

\section{INTRODUCTION}

CRM is basically a model which is used by organizations to manage their relations with the existing and future customers. It helps in automation of the services provided within an organization. It helps in organization and automation of the services provided by the organization. As a result it provides flexible and simple interface to the customers, which in turn helps in increasing company's Sales, Market, Branding, Customer Service, Technical support etc. CRM can have multiple possible variations in it [9], depending upon the organization's need. Every CRM is purpose specific and is used accordingly by the organization. CRM helps in tracking customer's interest and needs, so that organization can provide better support and help to its customers. It helps in retaining customers for a longer period.

As every aspect of technology is expanding in terms of cloud, CRM in cloud is also not behind. We can use CRM as a service in cloud. There are some small organizations which may not think to develop or buy CRM due to cost factor. In this paper they represent a CRM which can be used as a [11] service in cloud and organizations can pay according to their usage. It will provide exact sales target to the organization. Many large organizations have developed their own CRM and are using it on their own cloud, providing an ease to all employees in their work. There are many advantages of cloud customer relationship management (CRM) like Enhanced customer satisfaction and retention, Increased value from existing customers, Reduced costs associated with supporting and servicing customers, Profitability etc.

Mobile application development is a process in which they develop software for small devices such as mobile phones, tablets etc. The applications can be present in one of the following ways i.e. Preinstalled by manufacturer, Downloaded by customer from various mobile software distribution platforms or Delivered as a web application. The various execution environments for mobile software are Android [12] and Windows Mobile. The mobile application which has been developed so far works on two platforms i.e. android and windows.

Real Estate Based CRM in Cloud with Cross Platform Mobile App is a CRM which is build specifically for real estate companies. It can be used by every Real estate company from small size to larger size. It is a simple CRM which provides [6] maximum flexible and ease of use to customer. It can either be used as a service or can be used as a software by an organization.

\section{OVERVIEW}

CRM is a model which has been used from past many years and proved to be a game changing point in terms of revenue for many organizations. Including CRM in an organization is much easier for large industries as they can invest and can have their own. But when they talk about a start up, a small company cannot afford to invest in building its own CRM. From here cloud comes into picture, they have very few cloud CRM's e.g. SalesForce which allow organizations to avail pay-per-use facility rather than investing in building one's own CRM. But now in the world of big data, they need to have more and more leads through multiple sources which can further be analyzed for targeted business. The most important disadvantage of the existing CRMs is that they are very expensive. The current CRMs are confined to laptops or Pc's but now in the world of Smartphone customers prefer one touch services.

A unique CRM service that is centrally managed and stored from cloud is smoothly distributed among the clients. The services of the CRM can be utilized by the users through many sources like web, smart phone apps, web application etc. What this does is, this project increases the spectrum of usability for the users to use from many sources and the whole point of managing such a large scaled application is easy 
monitored by the cloud technologies and the background admin panel. The research motivation is explained in the next section and how this unique CRM tries to change the entire course of enterprise application process.

\subsection{Present System}

A Customer Relationship Management system is one of the most intelligent systems used in enterprise organizations. The evolution of CRM has gradually developed from a singleton simple system to an advanced parallel-processing system. The access of the CRM was traditionally limited to front line employees and managers; the process of CRM was even more linear and inefficient previously. Moreover the centricity of previous CRM's was limited to employee and company. Popular organizations like Sales Force, Sugar CRM, Microsoft, Oracle and many more have made their marks in their own ways for enhancing the way they can use a CRM. The transition of processing in a CRM has happened from a tradition CRM for an organization to Social CRM these days. Social CRM is more customer driven rather than company driven and this elongates the dynamic characteristic of the system. This project focuses more to be a social CRM than the traditional one.

\subsection{Research Motivation}

The most important disadvantage which cannot be ignored about current CRMs is that they are expensive. Keeping in mind the factor of cost, they developed a Real Estate Based Cloud CRM with Cross Platform Mobile Application. Our CRM works in a different way and takes customer's experience to some next level where everything is simple, easy and centrally managed. The advantages of Cloud CRM are as follows:

- Cloud CRM has more sources of data for e.g. IVR, Mobile application, Web Interface.

- Since they have cross platform mobile application, a larger set of customers can be covered.

- Inventory management system helps in managing utilizing resources more efficiently.

- Campaigning of generated leads can be done through Bulk-SMS and Bulk-Emailer.

- Our CRM is not confined to laptops or systems for lead generation as they have mobile application as well as IVR.

- Lead Management System filter all leads and converts a cold lead into hot lead resulting in a "sale made".

- And the most importantly this CRM has been hosted on a Microsoft Azure Cloud to compensate cost making it more effective.

\section{MODULES}

Real Estate based CRM in Cloud With Cross Platform Mobile Application is for Real Estate services based organization; which has the record of Projects, Flats, Brokers, Payment details, commission details, loan etc. The modules are as follows: Payroll Management, Inventory Management, Booking, Leads, Bulk-SMS, Bulk-Emailer, IVR and Master Manager.

\subsection{Payroll Management}

Real Estate based CRM in Cloud with Cross Platform Mobile Application is for Real Estate services based organization; Payroll is the sum of all financial record of salaries of employee. It basically manages the accounting part of the company. It handles all incentives, wages, bonuses and deductions of the employee. The main aim of payroll department is to ensure that all the employees are paid accurately and timely with all necessary bonuses [7] and deductions. Here in CRM payroll management consist of details of all the employees, details of their department, their designation and their salary. Various functionalities are as follows:

- Add department: It adds various departments in an organization where en employee can work. There can be any number of departments.

- Add Designation: It adds various designations which are assigned to employees and the time of appointing them. Designations will be assigned according to department.

- Set salary: This form is used for setting the salary of an employee.

- Employee Registration: Since departments and designations have already been specified, now details of employees can be registered with a unique employee ID.

- Update Employee Information: This form can be used to view all the registered employees as well as update information of any employee. Update Salary: It is used to view salary slip as well as updating the salary if required depending upon the work done by an employee.

- $\quad$ Pay Salary: It is used to print the salary slip.

\subsection{Inventory Management}

Inventory management system primarily specifies the size and placement of stocked goods. It consists of list of all available properties. The customer can view Inventories and after that book [9] them accordingly. The administrator can add or delete inventories as well. The functions provided by inventory management are as follows:

- Add Inventory: By using this page any new inventory can be added and it will show hold and sold status of any inventory.

- View Inventory: It will show list of all inventories that has been added by the user. Moreover the user can perform editing and deletion operations on the added inventories in this section.

\subsection{Booking Management}

This module manages Booking portion. Whenever a customer wants to book a flat, plot, land etc. Booking form will appear. This will have following two options: 
- Booking form: In this customer details will come including property type, flat type, project type, cost, and mode of payment.

- Booking Details: This will show the details of the Booking for example name of employee who has booked, Inventory ID, Customer Details, Payment Status etc.

\subsection{Leads Management}

Leads play a major role for enhancing the growth of a business. Managing and implementing leads for better sales in every dimension helps for extensive growth of business. Lead Management is a very important part of the real estate CRM which allows managing and creating leads manually and dynamically by the Admin, [14] Team Leader and Executive. The process starts from fetching new leads and it continues rigorously until the lead is converted to a hot lead or sale made for that particular lead. This lead management system not only helps to manage and organize leads but the lead is nurtured even through this system. It is not only about the processing the smart notification system in it helps to keep a constant reminder about the processing that goes on in the organization. Following are the functionalities assigned to different type of users are:

- Admin: It can create Lead manually, view all the created Leads, import leads from external resources and add new employees to work on the lead.

- Team Leader: It can create lead manually and assign these leads to the executives that are in his team. It can even view all the leads that are assigned to his team.

- Executive: It can create lead manually and view his Leads.

- Manager: - It has the responsibility of one or more teams and it's his duty to monitor all the processes that is being processed in those teams. His standing just comes below the admin in the hierarchy tree.

- Telesales:- The primary responsibility of this designation is to communicate with the customers. There process is being monitored by the Interactive Voice Response System which gives a more transparent analysis.

\subsection{Bulk-SMS}

Bulk-SMS is a web application that allows to send a message to a group of users at a very faster rate. This is used by real estate organizations for campaigning their upcoming projects. It works in a similar way as various websites like way2sms works. Since it has been provided as a service, so various organizations contact to service providers and give them the list of mobile numbers. The service provides sends SMS to all
[6] numbers in a very faster rate. It can also be used as an application and provided to the organization for their personal use.

\subsection{Bulk-Emailer}

Just like Bulk-SMS, Bulk-Emailer is also an application. It is basically used for campaigning by companies. It is used to send emails at a very faster rate to a large group of users. Bulk emailer is one of the most reliable and accepted form of campaigning digitally in this generation. With the use of genuine email servers and professional emailer helps the organization to reach more audience in a limited time. The most important factor that makes it even more unique then Bulk SMS is that it is cheaper and more reliable. It is used in almost every field for upcoming projects. This application in a CRM focuses more on the managerial and promotion of the services and products that are provided by the organization. Starting from new letters to registered users to introducing new products that are launched by the organization, it helps to reach more audience more reliably and conveniently.

\subsection{IVR}

Availability is one of the major characteristic that an organization focuses on for its organizations. In the era of digital world, gone are those days when employees had to be available in their offices $24 \times 7$ for giving services to their customers. The Voice over Internet Protocol has transformed the way an organization maintains its availability and this is an important aspect of the cloud CRM. IVR uses the concept of virtual number with a help of which a person or a company can use a personal telephone number where customers can call $24 \times 7$. With one virtual number, an organization can add hierarchies of numbers of its employees that can guarantee their availability for attending there customers $24 \times 7$. It [15] helps in controlling the way of routing incoming calls and saves both time and money. It increases the availability of an organization. Through this system, a company never loses a lead and hence can make more profit. Moreover this system even helps in monitoring the calls that have been incoming to an organization, filtering the leads out of the data, analyzing the voice mails left by the customers, investigating the way the executives handle the customers by analyzing there audio calls and many more. IVR has been developed on Asterisk framework.

\subsection{Master Manager}

Master Manager is a super admin of this CRM. It provides following functionalities:

- $\quad$ Manage users: It manages all types of users.

- Manage companies: It manages all the companies. 


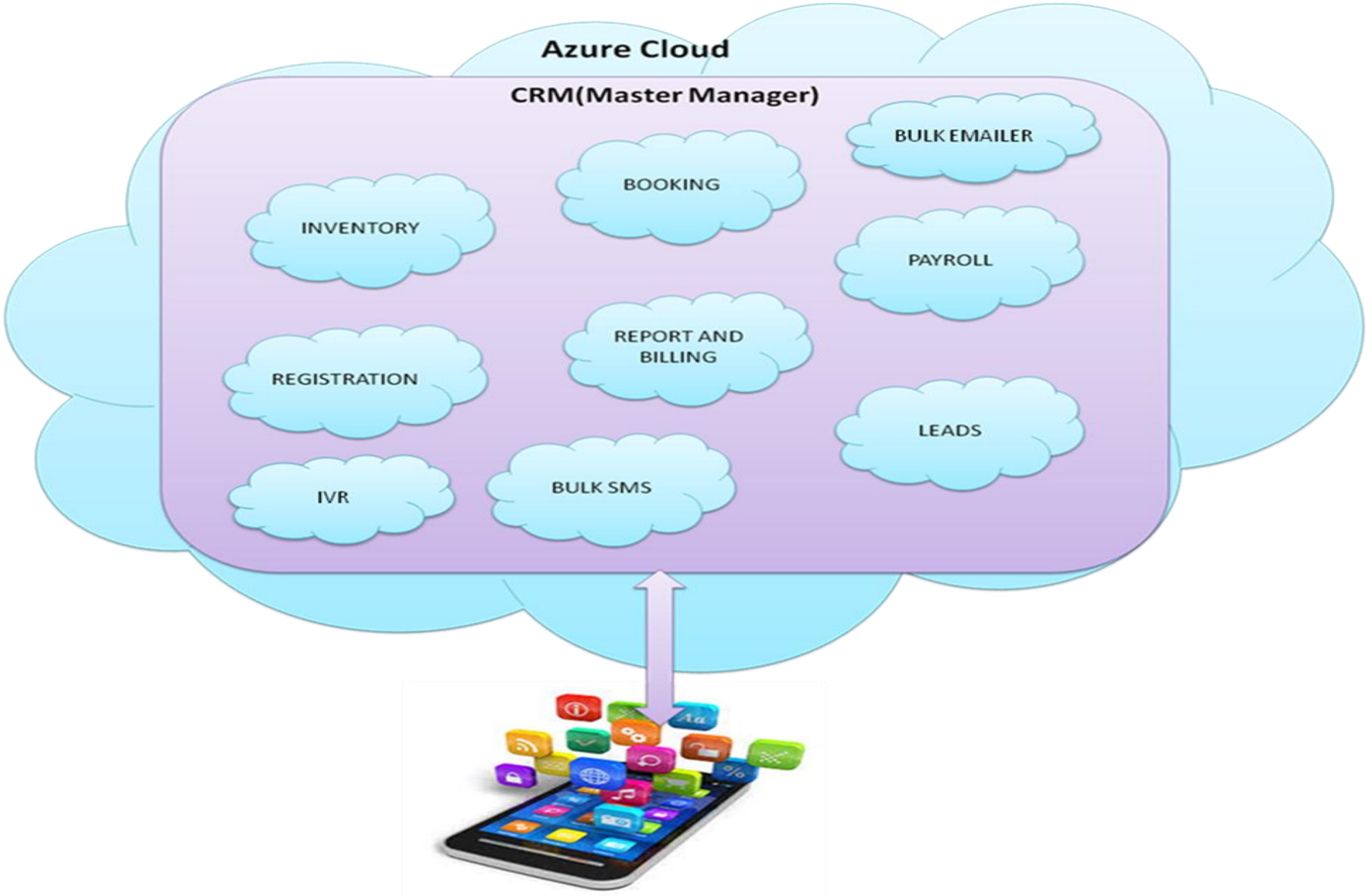

Fig 1. Architecture

- Manage Projects: It manages all the existing and upcoming projects.

It can also manage Team Leaders and Executives.

\section{METHODOLOGY}

The Real Estate Based Cloud CRM with Cross Platform Mobile Application has been developed using following technologies:

HTML5: HTML5 is a new standard for HTML. Apart from many new features introduced in HTML5, the most important is "validation". It makes the working of web pages more restrictive and prevents server from unnecessary computations and data flows. Validation is performed in all areas where it was required.

CSS3: CSS is used to control the style and layout of Web pages and it has got many standards out of which CSS3 is the one and is divided into "modules". We have used CSS3 to provide look and feel to user. It makes website more dynamic. It adds extra effects to web pages. CSS3 animations have been used to make layout of web pages more attractive. The main purpose to use CSS3 in this project is to make use of all latest technologies to make it more powerful.
ASP.NET 4.5:ASP.NET is a server-side Web application framework designed for Web development to produce dynamic Web pages. Almost all the modules of this CRM except Lead Management are created in visual studio 2010 as an ASP.NET website. In this project every module is combination of various web forms. Every module has its own

master page and style sheet. All modules are integrated under one module.

PHP 5.4: $P H P$ is a server-side scripting language designed for web development but also used as a general-purpose programming language. Here in this project PHP has been used to create one module i.e. Lead Management. It is an independent module, which keeps track of all the leads.

MySQL 5.3: MySQL is an open source relational database management system (RDBMS) that runs as a server providing multi-user access to a number of databases. This database has been used with PHP in the development of Leads Management.

SQL Server 2008: Microsoft SQL Server is a relational database management system developed by Microsoft.. Like MySQL, SQL Server has been used to store data of all the modules that were created in ASP.NET. We could have used any other database also. 
Azure SQL: Azure SQL database is a Microsoft product which extends capabilities of SQL Server to the cloud. Real Estate CRM has been deployed on azure cloud using Azure SQL Server. It offers on demand resource allocation and services.

Android Programming: Android programming has been used to develop a mobile application, which is an interface for the clients. Clients can use this mobile application for registering themselves to the company. The process of building an android application is developed to run from Android version 2.1 onwards.

Asterisk: Asterisk is an open source framework for converting a normal computer into a server that handles hardware communication. It supports PBX systems, VoIP gateways etc. activities through mobile applications are recorded and analyse for the benefit of the organization.

- Web Application: Apart from mobile application, a web interface is developed through which users can register by submitting a simple form.

- IVR: Interactive Voice Response is the most powerful source responsible for lead generation in this fast world of telecommunication where $24 x 7$ availability is an important concern. It provides an ease of access to customers and later on helps in targeted marketing as well.

As soon as leads are generated, lead management System comes into action. Lead Management System filter all the leads and provides an analysis to the employees which further

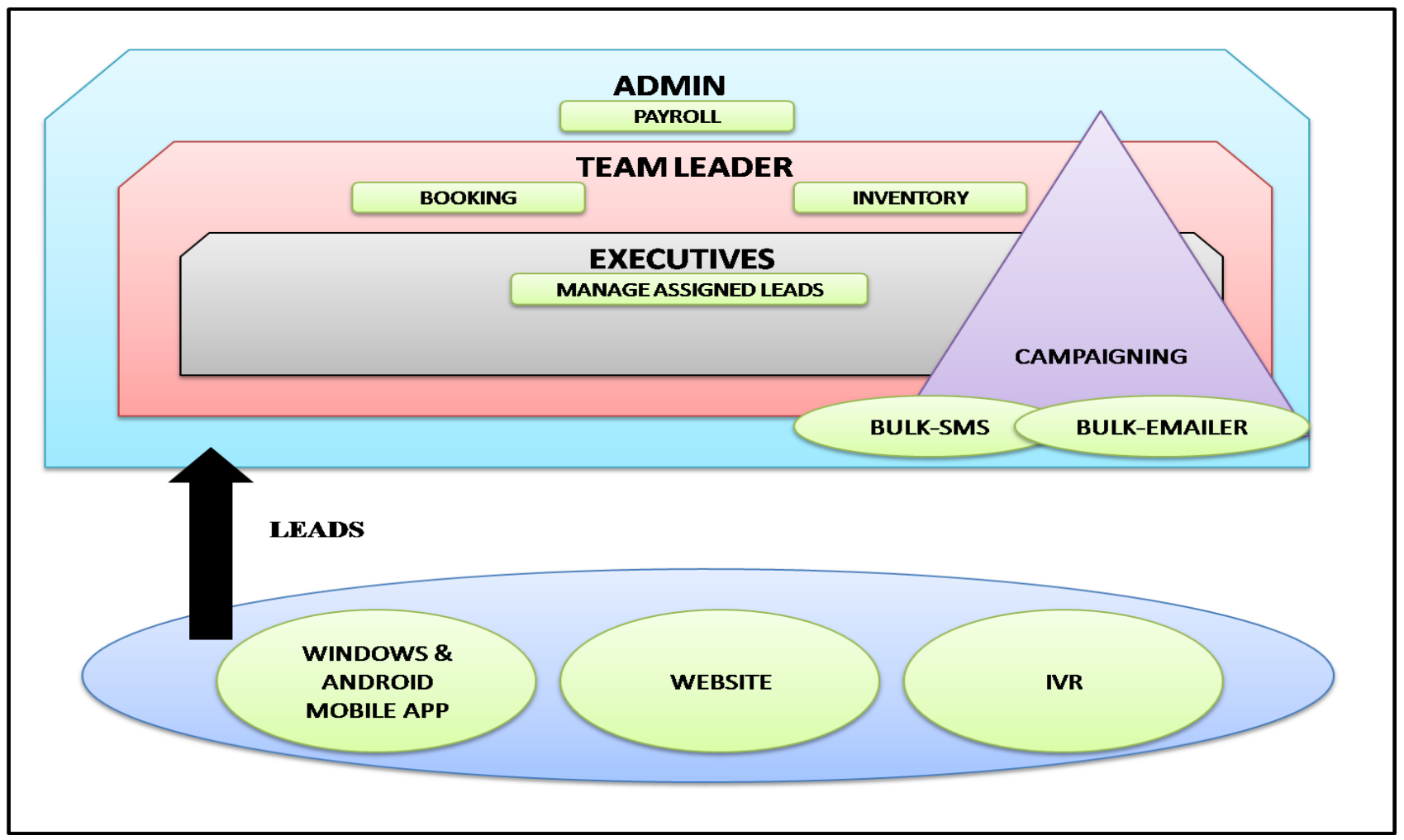

Fig 2. Workflow

\section{PROJECT WORKFLOW}

The main idea behind this project is to get maximum leads through various ways as possible. The workflow of the complete project is depicted in Fig 2. There are three source which are responsible for Lead Generation:

- Mobile Application: Two mobile applications have been developed on windows and android to provide one touch facility to users as well as to increase the domain of marketing. Through mobile application user can register for booking or send a query. All helps them to start their work. As they can see in diagram, there is a hierarchy of employees starting from Admin to team leaders followed by executives. Every user within the organization has different access permissions depending upon their designations. Admin is at the top of all and have all rights, out of which having access to the Payroll Management is the most important one. Payroll Management allows admin to manage salary slips and reports of all the employees of the organization. As they come down in the hierarchy, the next is Team Leader who manages all the leads and have rights to assign leads to other executives. Apart from leads, Team leader can have access to Booking and Inventory part of the 
project. Through inventory new projects can be added in the database and through booking registration can be done. The function of executive is to manage all the assigned leads. This hierarchy is not limited to executives and can be customized according to the needs of the respective organization.

There is portion in a diagram which is named as Campaigning. Campaigning is another important aspect of marketing. It makes use of Bulk-SMS and Bulk-Emailer by which advertisement can be done on a large scale through SMS and emails. All the employees of an organization including Admin have access to this functionality.

\section{IMPLEMENTATION \& RESULTS}

When it comes to implementation, this project is in a properly working state. All the methodologies discussed in section 4 of this paper has been used for its implementation. Security has been considered a crucial factor while implementation and unit testing is performed to validate each and every functionality of the system. Unit testing has been followed by integration testing and system testing as a whole. In this they can access the centrally managed data through a mobile application also. Below are some screenshots of the results followed by a graph in which a comparison has been shown between the two most leading CRMs with our cloud CRM.

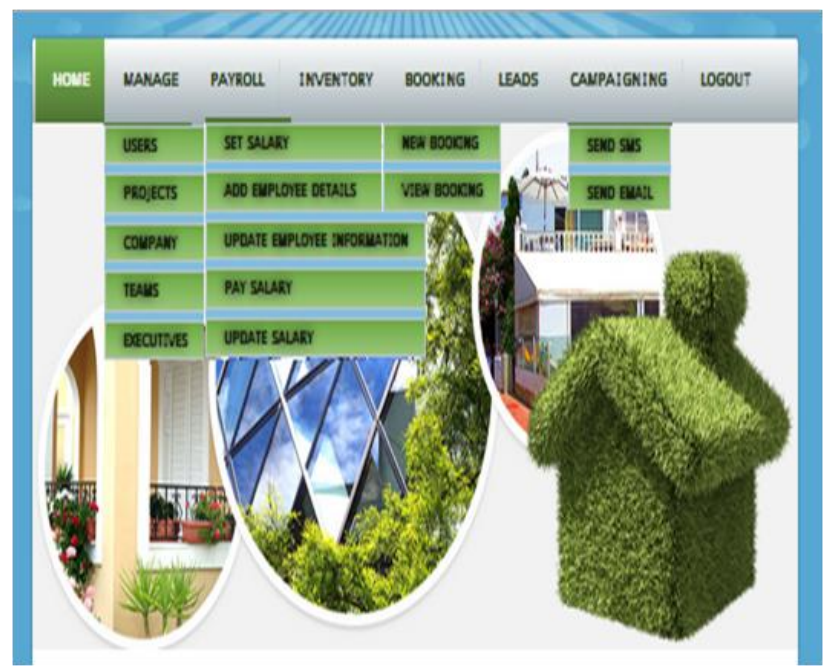

Fig 3: represents admin panel with all the menu options available.

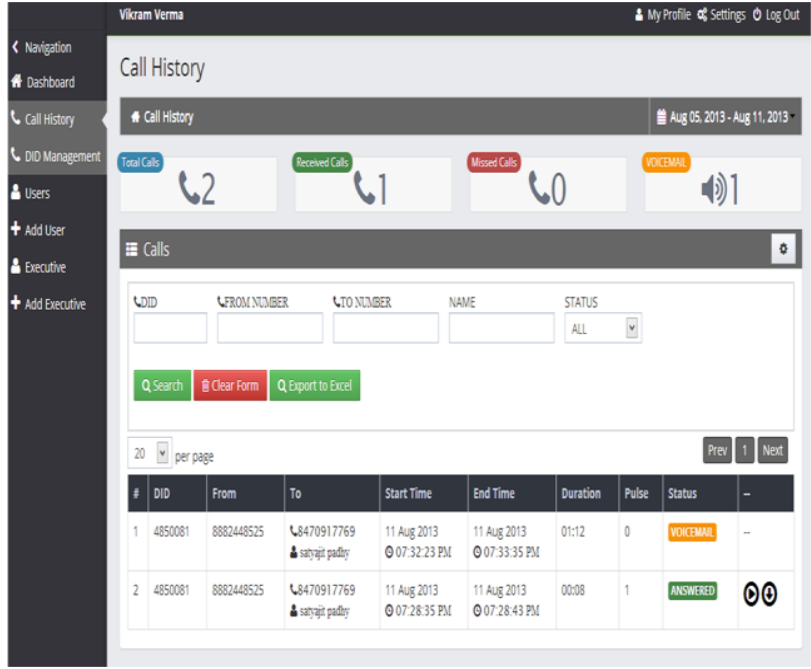

Fig 4 represents dashboard for IVR

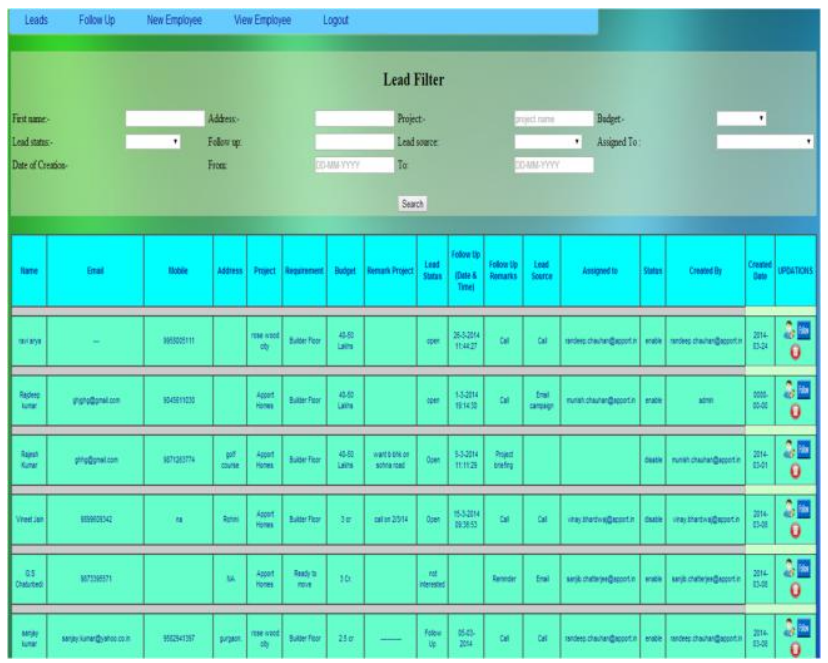

Fig 5 shows all the leads generated in a tabular form.

\begin{tabular}{|c|c|c|c|c|c|c|c|c|}
\hline HOME & MANAGE & PAYROLL & VENTORY & OKING & LEAOS & CAMPAIGNIN & \multicolumn{2}{|l|}{ LOGOUT } \\
\hline \multicolumn{2}{|c|}{ Company Registration No } & Name & Address & \multicolumn{2}{|c|}{ Service Tax No } & Telephone No & \multicolumn{2}{|l|}{ EMail } \\
\hline \multicolumn{2}{|l|}{368567} & twaris appartments & 51.21 sector 37 nodda & \multicolumn{2}{|l|}{8769898} & 98768566062 & Iammantwariffegnalicom & $\theta$ \\
\hline \multicolumn{2}{|l|}{454533332} & aran residencles & 34 nodd & \multicolumn{2}{|l|}{8349234} & 78998621213 & jarnofymalicom & $\theta$ \\
\hline \multicolumn{2}{|l|}{337968288} & yosits & goibadsedsecor? & \multicolumn{2}{|l|}{4349888} & 7898723456 & yphk360usustsin & $\theta$ \\
\hline \multicolumn{2}{|l|}{989883887} & jskbuilders & dethisec \& rohini & \multicolumn{2}{|l|}{78988879} & 7098832334 & 12pskitgmalcom & $\theta$ \\
\hline \multicolumn{2}{|l|}{3899783898} & kinj pesidenciles & noida sector 87 & \multicolumn{2}{|l|}{87838848} & 78349893348 & 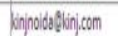 & $\theta$ \\
\hline \multicolumn{2}{|l|}{867872873} & johnsons & Brsectopyzgen & 89967867 & & 67832766966 & BSONSESSONSCON & $\theta$ \\
\hline \multicolumn{2}{|l|}{786787657} & rolits & ikpuram noide & 78767837 & & 8608782329 & tofofockspece com & 10 \\
\hline COUPANYES & & Coneany & wooress & semerow & & Felbrowe! & Guml. & 0 \\
\hline
\end{tabular}

Fig 6 shows panel for managing users. 


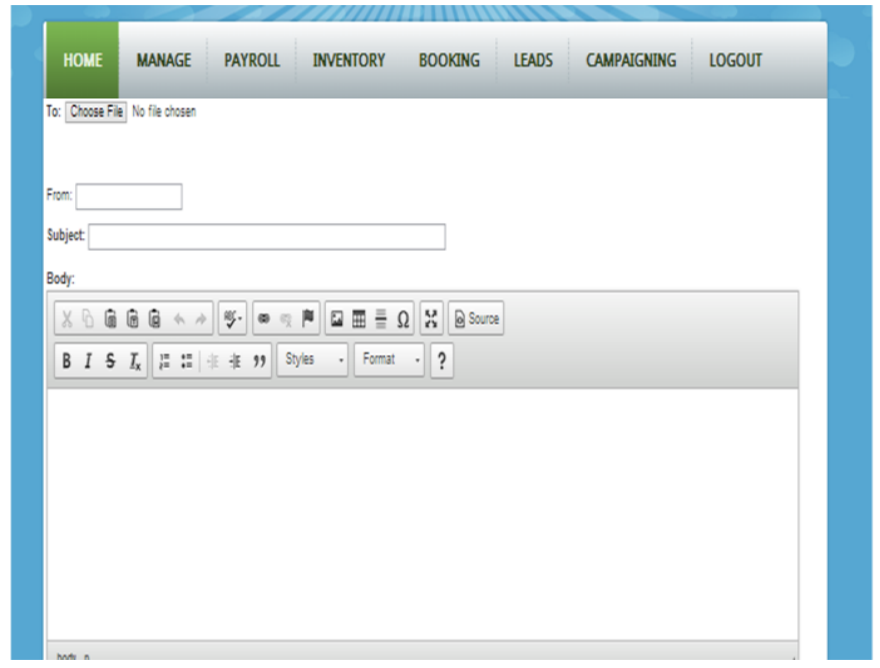

Fig 7 shows panel for Bulk-emailer.

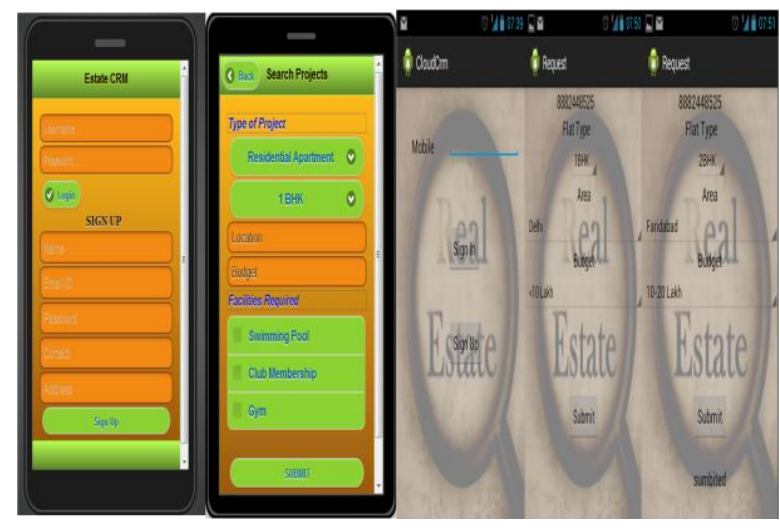

Fig 8 consists of screenshots of the mobile application for windows and android respectively.

\section{CONCLUSION}

This project is directed towards the real estate industry which is one of the booming fields of business around the globe. Pre definitely both real estate industry and CRM services are the next big thing for years to come. Keeping an optimistic idea in our toolkit, this project is a cloud based CRM for the real estate [6] industry. This CRM is dynamic in nature and includes a professional interface both for the customers and internal employees of the CRM availing organisation to implement it. Undoubtedly the implementation of this entire project in cloud makes it one of the most important aspects of this project. Deploying in cloud allows the resources to be allocated dynamically and flexibly for running the application at a faster rate and reliable mode. Another advantage is the low cost factor since the organisation has to pay only for the space it has used in the cloud.

The entire CRM application is built with an attractive and professional look and feel by making use of HTML5, CSS3 animations, JQuery and Javascript. The entire application in monitored centrally 24/7 with the volume of incoming requests,[8] available network bandwidth, amount of memory deployed for processing, number of virtual machines in cloud processing requests in parallel etc. Every module of this project is synchronised with a single database including the mobile application back end data which makes the schema of the data storage source to be unified. Extensive attention is marked for the fact of backing up and security of customer's data.

There is even a mobile application developed for the customers to use it. In this world of Smartphone's and tablets, many users have started using these resources for surfing which allows the dimension of customers [7] using this application to increase efficiently. The mobile application is developed for Android and Windows environment. The database of this mobile application is even centrally stored in the cloud allowing it to synchronise from every dimension.

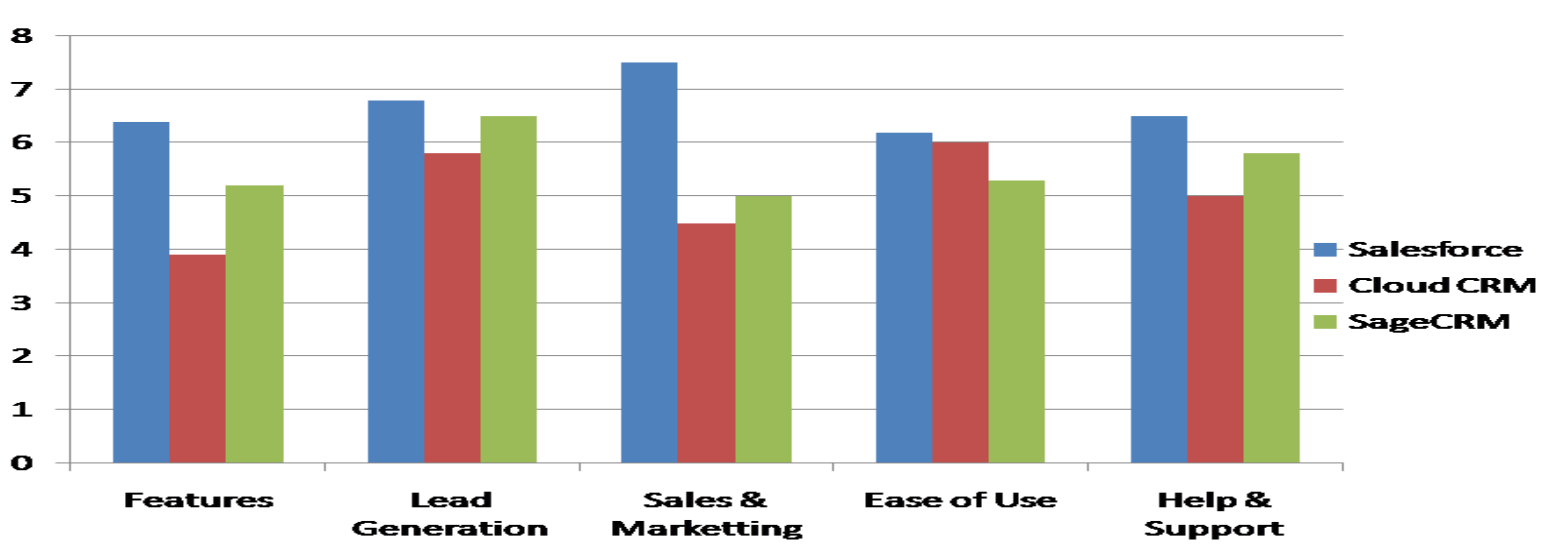

Fig 10 is the graph showing comparison between our clouds CRM with the world's leading CRMs 
The look and feel of the mobile application is kept very attractive and simple to use.

Marking the last words, the future of CRM is indeed projecting towards a brighter space and hence the motive of developing this application is to enhance the future to witness an improved technology. Many things will change in the year ahead, but one thing is predicted well ahead that the service of CRM will always be more demanding then never before since it changes the dimension of sales for a organisation.

\section{FUTURE SCOPE}

Customer Relationship Management is a more demanding feature in today's generation. Real estate in the other hand is another booming culture being developed all around the world. Every organisation from middle to larger scope needs to make use of CRM for better management of its employees, manage sales, better follow up with all its clients and keeping track of many details [8] inside the organisation. The future scope of this project needs to be projected in various key points. There are very few CRM that has been deployed in cloud and this has to be stated clearly that deploying this project in cloud has just broadened the dimension of CRM. The resources are more flexible to be deployed and the reliability increases with low cost of course. Featuring impressive services of this project from cloud, the modularity and parallel processing capability will be the two important factors for a brighter scope of future in near times.

There are several features related to the theory of CRM that appeals a lot for the future to be implemented in this project. Customer Touch Point is another dynamic feature that can be implemented which states that whenever a customer [9] accesses the real estate organisation's site, let it be by its website, call centre, mobile application or any other source the information about that lead will be dynamically available in all the resources at that instant of time. Traditionally CRM was supposedly built as one stand alone application which was supposedly by any type of industries. [6] Indifferently following a different path, every business model has different approaches for sales and hence keeping this in mind CRM must be developed specific to a business model and hence this project is directed to the best industry in the nation real estate.

Lead management system is the next thing in the world of CRM which helps to enhance the sales dominantly. The next thing that should be implemented and given a lot of attention are necessary features like knowledge management system, sales coaching system and service intelligent system to take the next big [7] step. Another important feature that needs to be enlightened is the merge of CRM with social networking platforms. There should be a placeholder in the CRM for customers facebook ID's, Linked in ID's. Twitter ID's etc for accessing there information from social networking sites for better lead management. The demographics of the customers is accessed via this technique. There can be even an implementation of capturing customer's conversations and monitor [6] their interests and thinking regarding the specified business model. By following this approach, the organisation can get a brief idea about the exact interests of customers towards their business services. The scope of developing mobile applications for every platform of mobile users can be the best step taken forward for generating more leads as the dimension of customers accessing the organisation resource increases. We will develop mobile application for Apple systems too.

\section{REFERENCES}

[1] Managing Software Requirements: A Unified Approach: Dean Leffingwell \& Don Widrig.

[2] Requirements Engineering Processes and Techniques; Gerald Kotonya \& Ian Sommerville; John Wiley \& Sons Publishing; March 2001

[3] Software Project Management: A Unified Framework by Walker Royce.

[4] The Unified Software Development Process by Ivar Jacobson, Grady Booch, James Rumbaugh.

[5] IEEE Std. 830-1993: IEEE Recommended practice for software Requirements Specification

[6] CRM Guru, Customer Relationship Management Answers, http://www.crmguru.com.

[7] ITtoolbox CRM, http://www.crmassist.com

[8] CRM - Forum, http://www.crm-forum.com

[9] searchCRM.com - The CRM Specific Portal and Search Engine

[10] whatis.com, http://www.whatis.com

[11] Windows Azure documentation, http://www.windowsazure.com/en-us/documentation/

[12] Android Development, http://developer.android.com/

[13] Windows Mobile App Development, http://msdn.microsoft.com/enus/windowsmobile/bb250560.aspx

[14] Leads Management System, www.leadssquared.com

[15] Asterisk Framework, http://www.asterisk.org 